\title{
An illustrated framework for the analysis of Web2.0 interactivity Peter Mechant (Ughent/MICT/iMinds)
}

\section{Introduction}

It is widely recognised that Western internet users have increasingly appropriated Web2.0 websites. Web2.0, understood as a large-scale shift towards a participatory and collaborative version of the web, enables internet users to 'get involved' and create or share content (Beer, 2009), thus supporting and mutually maximizing collective intelligence and added value for each participant (Hoegg, Martignoni, Meckel and Stanoevska-Slabeva, 2006). On Web2.0 platforms, content is not created internally at the internet companies (Jakobsson and Stiernstedt, 2010) but by the users themselves (Hudson-Smith, Batty, Crooks and Milton, 2009).

Several authors such as O'Reilly (2003), Jaokar (2006) and Hoegg, et al. (2006) emphasize the goal of Web2.0 websites and services. They state that "creating network effects through an architecture of participation" is the central principle of Web2.0 and that all other Web2.0 principles feed into this idea. Others explore the ideological meanings, the social, political and ethical implications of Web2.0. Scholz (2008), for example, argues that Web2.0 functions as a framing device. Other authors explore the role of Web2.0 as a tool or a framework for (peer) surveillance (Albrechtslund, 2008; Zimmer, 2008) or critique Web2.0 as the increased corporatization of online social and collaborative spaces and content (Jarrett, 2008; Petersen, 2008). From this viewpoint, Web2.0 does not provide an 'architecture of participation' (O'Reilly, 2003) but rather an "architecture of exploitation that capitalism can benefit from" (Petersen, 2008).

Although Web2.0 has become one of the central concepts in contemporary discussions about the internet, the actual meaning of Web2.0 is still subject to discussion with various authors emphasizing the hyped character of the phrase (Stern and Wakabayashi, 2007). Moreover, although the importance and significance of participation and engagement through interactivity on Web2.0 sites emerges in the literature, a contextual framework for the analysis of interactivity on Web2.0 sites in objective, structural terms as well as in subjective, functional terms is missing. 
The purpose of this article is to address this shortcoming by developing an analytical framework based on a conceptual analysis of interactivity. In the first section of the article the concept 'interactivity' is theoretically unpacked and approached as a multi-dimensional concept encompassing user-to-user, user-to-document and user-to-website interactivity. Next, an analytical framework, which takes into account structure and agency, is proposed. This framework for Web2.0 interactivity provides researchers with a descriptive vocabulary and a methodological approach for exploring the meaning and significance of Web2.0 sites for internet users. In the third section of the article the value and usefulness of this analytical framework is tested using a qualitative, small-scale and exploratory research design targeted at Flickr and deviantART users. Next, results are described and discussed, focusing on how participation on Flickr and deviantART is reflected in the use of their affordances. The article ends with a conclusion on the value of the proposed multidimensional interactivity-based approach for the study of agency and engagement of internet users and links this to the exploratory study of interactivity on Flickr and deviantART.

\section{Interactivity unpacked}

In most general terms, the phrase 'interactivity' describes an active relationship between two things. Interactivity refers to an activity that involves interaction but is also used to point to the property of being interactive. The phrase 'interactivity' is rarely specified or defined (McMillan and Downes, 2000; Rafaeli, 1988). Jens F. Jensen (1999) notes that there is no consensus on the characteristics or dimensions of interactivity within the scientific community.

Interactivity is a concept that is often mentioned in relation to new media and the (theoretical) discourse on new communication technologies. Since the mid-80's communication scholars, particularly in the discipline of Computer-Mediated Communication (CMC), have been working on the concept of interactivity (McMillan, 2002) and early in the study of the internet and the www, scientists identified interactivity as one of the main features of the Web. Hence, interactivity grew, especially in the early years of the new millennium, into a real 'buzz'-word. It became a concept that 
is often inappropriately used as a label or a selling point for new (communication) technologies (Quiring, 2009).

We distinguish three perspectives on interactivity in the literature (Kiousis, 2002; Leiner and Quiring, 2008; Quiring, 2009; Tremayne, 2008). These perspectives can be summarized as 'structure', 'process' and 'users' (McMillan and Downes, 2000). The first perspective ('structure') positions interactivity as a feature of a media technology, as "a measure of a media's potential ability to let the user exert an influence on the content and/or form of the mediated communication" (Jensen and Toscan, 1999, p. 59). The second perspective ('process') describes interactivity as a communication process. The focus here is not on the analysis of technological characteristics but on the study of interactivity as a form of information exchange between different parties. From this 'process' viewpoint interactivity is a "cyclical process in which two actors alternately listen, think and speak" (Crawford, 2002, p. 6). The third perspective ('users') approaches interactivity as "an informationbased process that takes place within the individual" (Newhagen, 2004, p. 397). This viewpoint studies the effect of interactive communication channels and emphasises the perception of the user. Interactivity thus becomes a "function of both the inclusion of interactive tools as well as of the language used when offering that tool" (Lilleker and Malagon, 2010, p. 27).

In general, three traditions of interactivity research are identified: human-to-human, humanto-documents and human-to-system interaction, focusing respectively on human communication, on how people interact with content or on how people interact with the computer (or any type of new media system) (McMillan, 2002). From within these traditions, interactivity refers to the features of a medium (its potential for interaction in general) and to the extent that people will use these features or affordances. An important approach to interactivity focusses on the information streams between sender and receiver. From this perspective it distinguishes three interactivity types: user-to-user, userto-document and user-to-website interactivity (McMillan, 2002; Szuprowicz, 1995).

\section{A framework for Web2.0 interactivity}


Using this distinction between user-to-user, user-to-document and user-to-website interactivity we create Figure 1 that describes the Web2.0 features that afford such interactions. We call these features the structural affordances of a Web2.0 site. Thus, the interactive potential of a Web2.0 site is expressed in the site's structural affordances, in user, document and website affordances.

Figure 1: structural affordances of a Web2.0 site

Roughly speaking, an affordance is what one system provides to another system, in our case what Web2.0 systems provide to their users. An affordance also encompasses the perceived functional significance of a website feature for an individual. Affordances have a complex if active history in ecological psychology and other disciplines (Hogan, 2009). For our purposes, we use the definition by Norman describing affordances as: "the perceived and actual properties of the thing, primarily those fundamental properties that determine just how the thing could possibly be used" (2002, p. 9).

User affordances encompass website features targeted at other internet users, enabling communication (e.g. a 'shoutbox' or an instant messaging tool), collaboration (e.g. a mutual events calendar) or networking (e.g. adding a 'friend' or joining a group). Document affordances refer to features that enable Web2.0 users to interact with content. For example, functions for search (e.g. a search box or a list with the most popular artists), features for content creation (e.g. assigning tags or writing comments) and features for user control (e.g. determining who is allowed to look at one's recent activities). Website affordances provide features for interaction between users and the websites, such as profile creation (e.g. adding a profile picture to the website), uploading content, adaptive interactivity (e.g. content customization or changing the look and feel of the website) and social awareness (e.g. consulting the recent activity of a user).

Affordances are a supremely relational concept because they link the external environment and internal states of mind. As affordances are the things that we recognize rather than the networks or website structure that we infer, they offer a key and under recognized link in a theory of structure and agency (Hogan, 2009). Web2.0 sites assemble a cohesive set of structural affordances that 
correspond closely to the website's goal and users. Thus, insight in the structural affordances of a Web2.0 platform, provides knowledge about the performative infrastructure that the website supplies to internet users.

\section{Functional affordances}

As Web2.0 sites offer integrated affordances and boundaries around which Web2.0 users participate, insight into how these structural affordances are used is essential in order to analyse how agency and engagement of Web2.0 users is expressed. Thus, we also need a framework that describes how internet users engage and interact with the structural affordances mentioned above. Hence, we suggest to add a set of functional affordances (see Figure 2), namely inter-action, intra-action and outer-action affordances.

Inter-action affordances refer to the use of structural affordances for communication. Interaction affordances, as the means for a communication process, reflect the use of structural affordances from a 'process' viewpoint; as a form of information exchange between two or more internet users. They enable conversations (see also 'conversational affordances' (Reid and Reid, 2010)) and can be described as 'social' affordances. We use the work of Hwang, et al. (2009, p. 225) to define intraaction affordances as affordances enabling interaction "from a person to himself/herself and time separation is essential (as space separation is not applicable). As the individual receiving the message is (due to time separation) in a different state from the moment when the message was issued, the message is likely to contain something 'new' and hence, valuable to the receiver, something that is not in his/her immediate field of attention, and yet, pertinent to his/her overall goals". Intra-action does not refer to a mental or cognitive process but describes the process of external representation of the mental process. Hence, intra-action affordances can also be called 'personal' affordances. Building on the work of Nardi, Whittaker en Bradner we describe outer-action affordances as affordances supporting "a set of communicative processes outside of information exchange, in which people reach out to others in patently social ways to enable information exchange" (2000, p. 79). Thus, outer-action affordances enable negotiations about availability, enable finding ways to establish 
connection, and enable the work of managing the progress of an interaction. We describe outer-action affordances as 'context' affordances. Outer-action affordances scaffold information exchange and play an important role in awareness systems intended to help people construct and maintain awareness of each others' activities, context or status.

Figure 2: functional affordances of a Web2.0 site

Functional inter-action, intra-action and outer-action affordances are rarely used independently. For example, structural affordances may be first used as outer-action affordances communicating a simple greeting in the Web2.0 environment or indicating a person's availability. Next, once rapport is established, structural affordances may be used as inter-action affordances supporting communication between the website users. After the conversation, an internet user might use a structural affordance as an intra-action affordance, for example by tagging or storing parts of the conversation as a message to oneself at a later moment in time.

\section{Structural and functional affordances as a twofold framework}

Combining the structural and functional affordances typology results in a twofold analytical lens or framework enabling us to describe interactivity on Web2.0 sites in objective, structural terms as well as in subjective, functional terms. Structural affordances show us Web2.0 as a space of objectoriented user, document and website affordances. Functional affordances describe Web2.0 as a space of perceived inter-action (social), intra-action (personal) and outer-action (context) affordances. This twofold framework for Web2.0 interactivity thus takes into account structure and agency, synthesising both the structural properties of the Web2.0 environment as well as the ways that users perceive and interact with these capabilities.

Web2.0 users will often resort to user affordances (as social affordances) to setup conversations with others, they will use document affordances (as personal affordances) to interact with the Web2.0 content, and they will often use website affordances (as context affordances) to 
communicate and interact with the Web2.0 platform itself. This shows that there are strong parallels between both components of the twofold analytical framework. Juxtapositioning structural and functional affordances shows that (1) structural user affordances can be linked to functional interaction or 'social' affordances; (2) structural document affordances can be linked to functional intraaction or 'personal' affordances; (3) structural website affordances can be linked to functional outeraction or 'context' affordances. Figure 3 summarizes the components of the twofold framework for the analysis of interactivity in Web2.0 environments.

Figure 3: components of the twofold framework

Although we hypothesise strong parallels between the structural and functional component of our analytical framework, their relation sometimes differs. Such deviations or differences are of utmost importance and emphasize the true meaning or significance of the Web2.0 site for the user(s), reflecting his or her commitment and engagement on that site. Literature on 'tagging' (assigning labels to content) for example, shows that 'tagging' as a structural document affordance is used as a functional intra- and outer-action affordance (Golder and Huberman, 2005, 2006; Hammond, Hannay, Lund and Scott, 2005). In other words, some users tag as part of an externalisation of a personal and cognitive process, assigning organisational or selfish tags for their personal benefit our goal (tagging as using an intra-action affordance), while others assign social or altruistic tags for yet others to retrieve and use (tagging as using an outer-action affordance).

\section{Applying the framework to the websites Flickr and deviantART}

\section{Flickr and deviantART}

In order to test the value and usefulness of the analytical framework we setup a small, qualitative research design. Our goal was to use the developed framework to explore how agency and engagement on Web2.0 sites is reflected in the use of Web2.0 affordances, and thus demonstrate the 
usability and value of the developed framework. We decided to apply this research question to two Web2.0 sites: Flickr.com and deviantART.com. Our research question was formulated as: "How is agency and engagement of Flickr users and deviantART users reflected in the use of the websites' affordances?".

The first website, Flickr, is often mentioned in the literature as an archetypical Web2.0 site (e.g. Alexander, 2006; Breslin, Passant and Decker, 2009; Cox, 2007; Maness, 2006; Miller, 2005; O'Reilly, 2005; Pissard and Prieur, 2007; Prieur, Cardon, Beuscart, Pissard and Pons, 2008; Valafar, Rejaie and Willinger, 2009) and was launched during the Web2.0 hype in February 2004 by the couple Stewart Butterfield and Caterina Fake out of one of the components of the online multiplayer game 'Game Neverending' (Prieur, et al., 2008). The website enables internet users to access a huge repository of photographs and to a lesser extent (short) video clips. Registered users can upload photographs and video clips on Flickr and can share them with others. They also have affordances at their disposal to edit, enrich and organize their content and to network and communicate with other Flickr users. Each registered Flickr user, also known as 'Flickrite', has a profile page and a page displaying the user's 'photostream'. Registering on Flickr is free. However, users who pay a small fee have access to premium services not available for non-paying users. The British Journal of Photography reported early 2009 that Flickr had 47 million members (Laurent, 2009). On Flickr's helpfora a figure of similar magnitude is mentioned. However Valafar, et al. (2009), based on extrapolation network analysis, reported the figure of 25 million users. Flickr is among the top 50 most visited websites in the world according to the Alexa WebMonitor and is visited monthly by about 45 million internet users according to Google's Adplanner. For Flanders (the Northern part of Belgium), the region where the respondents were recruited, figures from DigiMeter, an annual survey on the adoption and use of ICT, show that about 5\% of the Flemish internet users have a user account on Flickr (De Marez and Schuurman, 2010, 2011).

The second site, deviantART, is less frequently associated with Web2.0 (e.g. Christodoulou and Styliaras, 2008; Conole and Alevizou, 2010; Rigby, 2008), probably because its launch was situated well before the phrase 'Web2.0' attracted lots of buzz and attention. deviantART.com was launched in the middle of the dot.com burst (August 2000) by Scott Jarkoff , Angelo Sotira and Matt 
Stephens as part of a larger network of music-related websites called the Dmusic Network. Although initially focussed on displaying skins (custom graphical appearances for software) the website took the concept further and moved toward an art community that was very lenient for 'deviant' artworks, ensuring their members freedom-of-expression with as few restrictions as possible. deviantART wants to enable emerging and established artists to exhibit, promote, and share their works within a peer community dedicated to the arts. Thus, deviantART users, also known as 'deviants', have profile pages and exhibition spaces (galleries). They can converse about art in one of the online discussion fora or in the chatrooms of deviantART. They have social networking features at their disposal and can comment on and interact with the artwork on deviantART (also known as deviations). deviantART is strongly status-focussed: by means of different punctuation marks in front of user names, the status of deviants is expressed (e.g. $\sim=$ member, ${ }^{*}=$ premium member, ${ }^{\prime}=$ senior member). Moreover, analogue to Flickr, internet users who pay a small amount, have access to premium accounts offering features not available or restricted for non-paying deviants. According to QuantCast.com deviantART is visited monthly by 26.7 million internet users. On deviantART, accounts can not be deleted, making it difficult to assess the total number of active registered deviantART users (about 25\% of deviantART accounts are presumed to be 'inactive' (Rosadiuk, 2008)). Figures, revealed by deviantART's CEO Sotira in his closing speech on occasion of deviantART's tenth birthday, show that deviantART counted 14.4 million registered users who submit 140000 deviations, add 1.4 million deviations to their favourites, place 1.5 million comments and send 220000 notes on a daily basis (Sotira, 2010). For Flanders, no membership figures exist. However, based on observations of the website and on earlier research on internet use in Flanders, we suggest that the percentage of all the Flemish internet users participating on deviantART is significantly lower than on Flickr.

\section{Recruitment}

We chose a 'purposeful' sampling strategy and recruitment method (Patton, 2002; Strauss and Corbin, 1998), selecting information-rich research topics for in-depth analysis and study. Purposeful sampling 
is a form of judgment sampling where the researcher "actively selects the most productive sample to answer the research question" (Marshall, 1996, p. 523). We tried to recruit respondents that comply to a specific segmentation of Flemish media users, described as 'new media freaks' by DigiMeter (De Marez and Schuurman, 2010, 2011). These media users make up about $20 \%$ of the Flemish population and show the highest usage of computer, internet and Web2.0 sites. They also have the highest self-estimation in terms of digital skills and are the most active in adding online content. In order to select these respondents we used various criteria based on the description of the "new media freaks' segment (De Marez and Schuurman, 2010, 2011) as well as on group discussions and consultation meetings with university students and colleagues, a literature review of and (participative) observation on the websites Flickr and deviantART.

During the recruitment phase we targeted a 'maximum variety sample' (Morse, 1998), ensuring that the sample was heterogeneous with core observable commonalities of experience (Patmore, Qureshi and Nicholas, 2001). In order for a Flemish Flickrite to be recruited he or she had to comply to at least two of the following criteria: the number of photos uploaded had to be greater than 100; the number of memberships to groups had to be greater than 50; the number of favourites added to the profile had to be greater than 200 and/or; the person had to be a 'pro' Flickr user (has a paid, premium account). In order for a Flemish deviant to be recruited he or she had to comply to at least three of the following criteria: the number of deviations watched was greater than 1000; the number of deviations uploaded was greater than 50; the number of comments placed was greater than 100; the number of favourites added was greater than 500 and/or; the deviant account was created prior to February 2009 (deviantART member for at least a year).

It is important to note that, like any qualitative sample, ours does not claim to be representative for Flemish users of Flickr or deviantART. However, we are convinced that the sample consists out of internet users who frequently engage with new media and Web2.0 sites. In that sense all respondents can be categorized as 'new media freaks' or frequent Web2.0 users. This has some important methodological and theoretical implications. For one thing: the value of the developed framework can only be assessed for the study of this type of internet users. Also, results and 
conclusions on the agency and engagement on Flickr and deviantART need to be interpreted in this context and cannot be generalized to those who use the same technology (far) less frequently.

\section{Sample description}

In total 27 respondents were recruited (12 deviants and 15 Flickrites) with an average age of 27.4 years. Sixty per cent of the sample was male $(\mathrm{N}=16)$. The majority of the respondents $(\mathrm{N}=18)$ spent more than 2 hours online on an average day. Only a small fraction of the sample $(\mathrm{N}=3)$ spent less than an hour online on a daily basis.

Table 1: Flickr respondents

The recruited Flickrites were very Web2.0-savy, with all of them having a Facebook account and with more than two thirds having accounts on instant messaging applications and social bookmarking websites. Also, more than half of the respondents $(\mathrm{N}=8)$ managed a weblog. The same goes for the recruited deviants: except one, they all had a Facebook account. Also, the majority had an account on YouTube. Similar, to the Flickr respondents eight out of the twelve deviantART users had a weblog.

Tables 1 and 2 show how the deviantART respondents posted on average 177 deviations. For Flickr, this numbers is much higher: the Flickrites that were interviewed posted on average 3565 pictures. For further descriptive information see tables 1 and 2.

Table 2: deviantART respondents

Questions and coding methodology

Between February and March 2010 we interviewed the 27 respondents separately using a semistructured topic list (Fontana, 2002; Fontana and Frey, 2005). An interview took an average 80 
minutes. The interviews took place, as far as possible, in the vicinity of a computer so that the respondent could log in to his/her account and illustrate his/her statements, habits and practices.

The semi-structured topic list served as a 'guide' during the conversations with the respondents and consisted out of questions on: (1) the usage of the website and the meaning that respondents assign to the website; (2) interactivity with other website users and the social aspect of using the website; (3) interactivity with the (user-generated) content on the website and; (4) interactivity with the website itself.

In order to apply the twofold analytical framework that we developed, we used a deductive methodology to code the transcripts of the interviews. A deductive methodology enables coding through a predefined (theoretical) perspective (Berg, 2001). Deductive coding encompasses three coding phases (Miles and Huberman, 1994). In the first phase descriptive codes are assigned to text snippets based on predefined areas of interest, whether factual, thematic or theoretical in nature (Lewins and Silver, 2007). We used the structural component of the twofold analytical framework encompassing three interaction classes (user, document and website interaction affordances) to assign codes describing the usage of the website features, thus gaining insight into which website features were used. Next, interpretative coding took place, digging deeper into the meaning of the descriptive codes. Here, we used the functional component of the twofold analytical framework encompassing three interaction classes (inter-, intra-, and outer-action affordances) in order to describe how and why website features were used. Finally, moving on to a more inferential and explanatory level by examining the parallels, differences and oppositions between the descriptive and interpretative codes, we assigned pattern codes.

In this way, codes describing which website features were used were juxtapositioned to codes describing how and why these features were used. Using the structural component of the twofold analytical framework to assign descriptive codes, and using the functional component of the twofold analytical framework to assign interpretative codes enabled us to compare, during the process of assigning pattern codes, the (technological) structure of the website with how the website is actually perceived and used. This cyclic coding process was iterated several times until no further insights could be extracted from the texts. 


\section{Results and discussion}

Our research question targets agency and engagement on Flickr and deviantART and addresses how participation on a Web2.0 platform is reflected in the use of the website's affordances. We structure our results in three sections. First we describe how the structural user affordances of Flickr and deviantART are used. Next, we focus on document affordances on both websites, in specific on website features enabling tagging, faving and commenting. Finally, the usage of the website affordances of Flickr and deviantART is addressed. In each section, we will also analyse these practices in terms of inter-, intra- and outer-action, thus reflecting on their functional significance.

User affordances

We defined affordances targeted at other internet users as structural user affordances. From a functional perspective, these are closely linked to inter-action or social affordances. Although our data shows that, in general, user affordances are seldom activated by our respondents, we did find various examples of how users manage these affordances to converse, interact and network with others.

In contrast to the Flickr interviewees indicating that they do not send private messages (FlickrMail) or use the website extensively for networking, most Flickr respondents did mention that they actively seek membership of Flickr groups. Joining a group however not only functions as an inter-action or social affordance. It also has a very important role in creating an audience or a public for one's photographs which illustrates how the affordance to join a group is used as an outer-action or context affordance scaffolding future interactions:

"The first group I joined was the group 'ScoreMe', because members give points to each other's pictures. Now, I take pictures and then I start looking for groups where I can post my pictures. Especially in order to get comments on them" (Bart, Flickr pro, 22 years). 
Except for the user affordance to create or join groups, most user affordances (enabling for example sending a private message or adding a contact to one's Flickr network) were not key for the Flickrites that we interviewed. Isolde's quote is typical for their position:

"I like Flickr for the photos, and my photos especially, but the whole system of Flickr is not really for communication or interaction. The focus is only on those photos. Given that there is such a thing as Facebook, why do something else, why should I look for something else?" (Isolde, Flickr free, 30 years).

deviantART offers, in contrast to Flickr, a broad range of user affordances, enabling both synchronous and asynchronous interpersonal and group communication, as well as networking with other deviants and the surveillance of the work of others (through the deviantWATCH affordance). We noticed that these user affordances often serve as inter-action affordance enabling deviants to discuss a wide variety of topics in a wide variety of groups:

"I talk about anything and everything. That can really vary. It might be about politics, for example when there are elections ... but also about stupid things in groups such as 'LOLcats'. So ... it can sometimes be very serious but also very brain-less" (Niels, deviantART member, 20 years).

\section{Document affordances}

Structural document affordances are interaction features targeted at Web2.0 content elements. These document affordances are closely linked to intra-action or personal affordances from a functional perspective, reflecting the externalisation of a cognitive process. We will discuss tagging, faving and commenting as the use of three main document affordances, enabling interactivity with Web2.0 content.

Our interviews show that on Flickr the document affordance 'tagging', is mainly used as an 'intra-action' affordance, as a means to communicate to oneself or organize photographs for oneself. 
In addition, 'tagging' also serves as an outer-action affordance, because assigning sufficient and clear labels to one's photographs helps making them visible and searchable. Likewise, on deviantART, 'tagging' content is most often an 'intra-action'. Moreover, as outer-action, the inappropriate use of tags is despised by all deviants we talked to:

"Yes, I tag my deviations, but I do not misuse the system. I assign 'to-the-point' tags such as 'make up', 'wig', 'medieval' or 'fantasy' and such. But I do not misuse tags. That is very annoying; some people tag their deviations with tags such as 'sex', 'porn' or 'girls'. Others use very generic words, thus polluting the search system. I hate those kind of deviants!" (Britt, deviantART premium, 22 years).

With regards to 'faving' (adding a content element to his or her list of favourites) we notice two functional dimensions. Most Flickr and deviantART respondents indicated that they primarily use this document affordance type to add a photograph or an artwork to his or her private collection of interesting and beautiful photographs or artworks, thus creating an own art or photography collection (using the document affordance as an intra-action affordance). Other Flickrites or deviants told us that they add content to their favourites because, in this way, they can communicate their appreciation to the photographer or artist (using the document affordance as an inter-action affordance). The following quote shows that the 'faving' affordance can be used alternately as a social or inter-action affordance or as a personal or intra-action affordance:

"Sometimes I assign photos of others to my favourites. Sometimes, I do this to show the creator that I find his or her work really good, without having to put much effort in it. Most often however, I just try to create a collection of beautiful things" (Jenny, Flickr pro, 39 years).

Our respondents use commenting, the last document affordance that we discuss, sparingly. Often they refer to the phatic or trivial character of most comments to explain why they do not use this structural document affordance. Still, sometimes comments are used to gather and give constructive, positive 
feedback on others' work and to start conversations. We note that the respondents use this document affordance as a social affordance: they seek a conversation or a dialogue about the photograph or artwork:

"When I want to give a comment, it is never a comment like 'nice picture' or 'well done'. I find such comments pointless and try to offer real feedback. I write, for example, 'That's a pretty composition with that pole on the right ..., well done, I would do it a bit more so and so'. There are so many 'empty' comments written on the internet that it gets on my nerves sometimes" (Tony, Flickr pro, 30 years).

In this respect we want to point to the special document affordance 'Critique'. This affordance was implemented in April 2009 on deviantART and is only available to premium deviantART members. 'Critique' was created to avoid the phatic or meaningless content that was submitted through the 'normal' comment affordance of deviantART. The 'Critique' feature was introduced to enable substantive criticism and feedback on deviations. deviantART emphasizes the profound, thoughtful and respectful character of a 'Critique' describing it in their Frequently Asked Questions-section (FAQ) as: "designed to help artists get in-depth, critical feedback and commentary on their work. (...) The Critique system co-exists with the original comments system but provides a space that is designed for considered, thoughtful and RESPECTFUL criticism".

\section{Website affordances}

Affordances that target interactivity with the Web2.0 website itself were defined, from a structural perspective, as website affordances. These affordances are, from a functional perspective, closely linked to outer-action or context affordances, enabling users to create a social framework and conditions that can support them in their future actions on the website. 
Of course, both on Flickr and deviantART, the website affordance to upload content is of utmost importance for our respondents. This affordance enables them to share their content and strive for 'publicity'. Moreover, the website affordance of deviantART to upload content is appreciated and used because of its flexible, open and lenient character:

"I attend drawing classes and I now regularly draw nudes. The advantage [of deviantART] is that I can upload those drawings and sketches without being blocked. Other websites, for example a social networking such as Netlog, block such content. When you are repeatedly blocked, they even deny you access" (Mark, deviantART member, 37 years).

Our respondents also presume the willingness to share and do not appreciate people who use the upload affordance as a means to create a personal, private archive of content, shared with no one:

"It is really a shame to use Flickr as a mere photo bucket, as a mere online repository. I use Flickr to share my photos and learn or pickup ideas from others. If nobody would share his or her photographs that would not be possible" (Natalie, Flickr free, 22 years).

Especially interesting are website affordances that communicate information from the website to the website user. Two of those website affordances are 'social navigation' and 'social browsing'. 'Social browsing' refers to content exploration based on the practices, uploads and preferences of one's social network on the website. 'Social navigation' refers to content exploration based on the practices, uploads and preferences of the whole website community. Our interviews show that both affordances, enabling adaptive interactivity between website and website user, are frequently used.

'Social browsing' was spontaneously mentioned by most respondents as an important way to meet new and interesting content on Flickr or deviantART: 
“What I really like is to see my contacts' new photos. I take pictures with a Lomo ... in the Lomo group, of which I am member, every day new photographs appear and that's just interesting” (Isolde, Flickr free, 30 years).

'Social navigation' is also supported by website affordances. An example on Flickr includes the 'Interestingness' page that shows the 500 most interesting pictures of that day based on an algorithm that takes into account where the clickthroughs on a photo are coming from; who comments on the photo and when; who marks the photo as a favourite; its tags and many more things which are constantly changing.

Another website affordance supporting Flickrites in their practice of taking photographs is the automatic display of the Exif (exchangeable image file format) data of photos which helps them to gain insight in the technical aspects of a particular photograph. On deviantART we encountered website affordances supporting adaptive interactivity such as the possibility to tweak content presentation to show only content that fits the interests of the deviant. Other website affordances of deviantART support social awareness, displaying, for example, a community mood (the aggregation of individual moods of the deviants). Again, website affordances function as outer-action affordances, creating awareness of the communication environment and helping deviants to understand the website's context, thus supporting (future) inter- and intra-action.

\section{Conclusion}

We conclude that the twofold analytical framework, developed in this article, enables us to describe the interactivity that plays out on Flickr and deviantART. In specific, the framework provides insight in the agency and engagement of 'new media freaks'. The framework allows us to describe both websites in objective, structural terms as spaces of user, document and website affordances. The framework also makes it possible to talk about the two websites in subjective, functional terms, describing them as spaces of perceived inter-action, intra-action and outer-action affordances. The framework thus has three important merits. 
Firstly, it enables us to interpret Web2.0 as a medium 'through' which internet users can communicate, as well as a medium 'with' which internet users can communicate. This perspective breaks with the instrumental view that considers, both in name and in function, the internet as an instrument or medium. Nowadays, Web2.0 websites actively participate in communicative exchanges as a kind of additional agent and/or (inter)active co-conspirator in the interaction between Web2.0 users. Web2.0 platforms take the position of a social actor with whom one communicates and interacts, challenging long standing assumptions about the role and function of technology.

Secondly, the elaborated framework allows for the analysis of Web2.0 sites as spaces where interaction 'goes beyond' the mere consultation and selection of content, as spaces supporting the (co) creation of content and value. In this respect, the framework can describe new communication patterns that extend on the four "ideal information-patterns" formulated by Bordewijk and van Kaam (1986) (see also Hoem, 2006).

Thirdly, the framework takes into account structure and agency and helps us to understand processes of collective or individual agency, thus enabling further insight into the emancipatory or participatory potential of these spaces. This emancipatory power of the internet and its potential to revitalise democracy, is being increasingly critically approached after a period of celebratory chronicles about the internet and the web (Curran, Fenton and Freedman, 2012).

Moreover, describing interactivity on Web2.0 sites in terms of affordances enables us to focus on the relationships between users and the Web2.0 site because the concept 'affordance' makes a connection between (the properties of) the environment (the Web2.0 site) and the cognitive and mental processes among the users of those sites. With our twofold framework we integrate both the structural properties of Web2.0 (structure) and the ways that users interact with these capabilities (agency). The twofold framework thus takes into account human agency as well as the technological tools and components of the Web2.0 environment.

We can also conclude that the majority of our respondents consider Flickr and deviantART to be a meeting place for photo- or art lovers, suggesting that the sites are virtual 'third places'. Virtual 'third places' are places that exists outside the home and beyond the 'work lots' of modern economic production where people gather to enjoy each other's company (Oldenburg, 1999; Oldenburg and 
Brissett, 1982; Soukup, 2006). From a holistic viewpoint our results also confirm that new interaction affordances provided by media-oriented Web2.0 platforms are changing the ways in which amateur photographers or artists engage with other users. Not only do Web2.0 sites facilitate amateurs or consumers to (co)create (e.g. adding metadata), they also enable the reproduction and distribution of content (e.g. recommending a picture to their friends), and create possibilities to consume photographs or art in new and novel ways (e.g. through a personalized content stream enriched with metadata). Thus, Web2.0 websites are generating a new kind of media logic with regards to media consumption and production, a media logic that is expressed in the affordances of those websites.

For our respondents, Flickr and deviantART are sites, where, quietly under the surface or in full view of all, affordances are used to create spaces for engagement and community building. Both Web2.0 sites provide lots of user, document and website affordances that can serve as inter-action or social affordances. However, we noticed that these affordances are seldom used to engage in real conversations or to create an online consensus. In that respect, we also note a lack of commitment among our respondents who indicated themselves that the quality of the dialogues is often poor. In line with Papacharissi's (2008) claim that the internet is a public space but not a public sphere, we conclude that Flickr and deviantART are public spaces. This finding emphasizes the democratic potential of Flickr and deviantART, but also points to the effort and the work needed to fulfil this potential.

In this article, we described how Web2.0 users deploy Flickr affordances to gain access to a community of practice or a virtual third place. In that way, the practices of our respondents reflect Flickr's baseline: 'Share your photos. Watch the World'. We also described how deviantART, 'where art meets application', represents more than just a mere 'space' where one can share amateur art. For most of our respondents deviantART was more than a 'virtual settlement', for them the website acted as a 'virtual community'.

\section{Acknowledgments}


The research leading to this article was supported by IBBT (Interdisciplinary institute for Technology). We would also like to acknowledge Lieven De Marez and CSS's anonymous reviewers for their helpful comments on earlier versions of the article. 


\section{References}

Albrechtslund, A., 2008. Online Social Networking as Participatory Surveillance, First Monday, [online] Available at:<http://www.uic.edu/htbin/cgiwrap/bin/ojs/index.php/fm/article/view/2142/1949> [Accessed 20 July 2012].

Alexander, B., 2006. Web 2.0: a new wave of innovation for teaching and learning? Educause Review, 41(2), pp.33-44.

Beer, D., 2009. Power through the algorithm? Participatory web cultures and the technological unconscious. New Media and Society, 11(6), pp.985-1002.

Berg, B. L., 2001. Qualitative research methods for the social sciences. London: Allyn and Bacon.

Bordewijk, J. L. and van Kaam, B., 1986. Towards a new classification of teleinformation services. Inter Media, 14(1), pp.86-108.

Breslin, J. G., Passant, A. and Decker, S., 2009. The social semantic web. Londen: Springer.

Christodoulou, S. P. and Styliaras, G. D., 2008. Digital art 2.0: art meets web 2.0 trend, [online] Available at:<http://dl.acm.org/citation.cfm?id=1413667> [Accessed 20 July 2012].

Conole, G. and Alevizou, P., 2010. A literature review of the use of Web 2.0 tools in Higher Education. Milton Keynes: Higher Education Academy.

Cox, A., 2007. Flickr: what is new in Web2.0? Aslib Proceedings, 60(5), pp.493-516.

Crawford, C., 2002. Understanding interactivity. San Fransisco: No Starch Press.

Curran, J., Fenton, N. and Freedman, D., 2012. Misunderstanding the internet. Abingdon: Routledge.

De Marez, L. and Schuurman, D., 2010. Digimeter Rapport 2 Vlaanderen Wave 2 November-Maart 2010, [online] Available at:<http://digimeter.be/resultaten.php> [Accessed 20 July 2012].

De Marez, L. and Schuurman, D., 2011. Digimeter Rapport 3 Vlaanderen Wave 3 AugustusNovember 2010, [online] Available at:<http://digimeter.be/resultaten.php> [Accessed 20 July 2012].

Fontana, A., 2002. Postmodern trends in interviewing. In: J. Gubrium and J. Holstein, eds 2002. Handbook of qualitative research: context and method. Thousand Oaks: Sage, pp.161-175. 
Fontana, A. and Frey, J. H., 2005. The interview. From neutral stance to political involvement. In N. K. Denzin and Y. S. Lincoln, eds. 2005. The Sage handbook of qualitative research. London: Sage, pp.695-727.

Golder, S. A. and Huberman, A., 2006. Usage patterns of collaborative tagging systems. Journal of Information Science, 32(2), pp.198-208.

Golder, S. A. and Huberman, B. A., 2005. The Structure of Collaborative Tagging Systems, Cornell University Library, [online] Available at:<http://arxiv.org/abs/cs.DL/0508082> [Accessed 20 July 2012].

Hammond, T., Hannay, T., Lund, B. and Scott, J., 2005. Social bookmarking tools: a general review, D-Lib Magazine, [online] Available at:

<http://www.dlib.org/dlib/april05/hammond/04hammond.html> [Accessed 20 July 2012].

Hoegg, R., Martignoni, R., Meckel, M. and Stanoevska-Slabeva, K., 2006. Overview of business models for web 2.0 communities, [online] Available at: <http://www.alexandria.unisg.ch/Publikationen/31411> [Accessed 20 July 2012].

Hoem, J., 2006. Openness in communication, First Monday, [online] Available at: <http://firstmonday.org/htbin/cgiwrap/bin/ojs/index.php/fm/article/view/1367/1286> [Accessed 20 July 2012].

Hogan, B. J., 2009. Networking in everyday life. Ph.D. University of Toronto.

Hudson-Smith, A., Batty, M., Crooks, A. and Milton, R., 2009. Mapping for the Masses: Accessing Web 2.0 Through Crowdsourcing. Social Science Computer Review, 27(4), pp.524-538.

Hwang, W.-Y., Hsu, J.-L., Lee, A. T., Chou, H.-W. and Lee, C.-Y., 2009. Intra-action, interaction and outeraction in blended learning environments. Educational Technology and Society, 11(2), pp.222-239.

Jakobsson, P. and Stiernstedt, F., 2010. Pirates of Silicon Valley: state of exception and dispossession in Web 2.0, First Monday, [online] Available at: <http://firstmonday.org/htbin/cgiwrap/bin/ojs/index.php/fm/article/view/2799/2577> [Accessed 20 July 2012]. 
Jaokar, A., 2006. Tim O' Reilly's seven principles of web 2.0 make a lot more sense if you change the order, Open Gardens, [online] Available at: <http://opengardensblog.futuretext.com/archives/2006/04/a_web_20_faq.html> [Accessed 20 July 2012].

Jarrett, K., 2008. Interactivity is Evil! A critical investigation of Web 2.0, First Monday, [online] Available at: <http://www.uic.edu/htbin/cgiwrap/bin/ojs/index.php/fm/article/viewArticle/2140/1947> [Accessed 20 July 2012].

Jensen, J. F., 1999. Interactivity: Tracking a new concept in media and communication studies. In P. A. Meyer, ed. 1999. Computer Media and Communication. Oxford: Oxford University Press, pp.160-187.

Jensen, J. F. and Toscan, C. eds., 1999. Interactive television: TV of the future or future of the TV? Aalborg: Aalborg University Press.

Kiousis, S., 2002. Interactivity: a concept explication. New Media and Society, 4(3), pp.355-383.

Laurent, O., 2009. Getty images targets Flickrverse, British Journal of Photography, [online] Available at:<http://www.bjp-online.com/british-journal-ofphotography/news/1647691/getty-images-targets-flickrverse> [Accessed 20 July 2012].

Leiner, D. J. and Quiring, O., 2008. What interactivity means to the user. Essential insights into and a scale for perceived interactivity. Journal of Computer-Mediated Communication, 14(1), pp.127-155.

Lewins, A. and Silver, C., 2007. Using software in Qualitative Research. London: Sage.

Lilleker, D. G. and Malagon, C., 2010. Levels of interactivity in the 2007 French presidential candidates' websites. European Journal of Communication, 25(1), pp.25-42.

Maness, J. M., 2006. Library 2.0 theory: web 2.0 and its implications for libraries, Webology [online] Available at: < http://www.webology.org/2006/v3n2/a25.html> [Accessed 20 July 2012].

Marshall, M. N., 1996. Sampling for qualitative research. Family Practice, 13(6), pp.522-525. 
McMillan, S. J., 2002. Exploring models of interactivity form multiple research traditions. In: L. Lievrouw and S. Livingstone, eds., 2002. The handbook of new media. London: Sage, pp.163175.

McMillan, S. J. and Downes, E., 2000. Defining interactivity: a qualitative identification of key dimensions. New Media and Society, 2(2), pp.157-179.

Miles, M. and Huberman, A., 1994. Qualitative data analysis: an expanded sourcebook. London: Sage.

Miller, P., 2005. Web 2.0: Building the New Library, Ariadne, [online] Available at:<http://www.ariadne.ac.uk/issue45/miller/> [Accessed 20 July 2012].

Morse, J., 1998. Designing funded qualitative research. In: N. K. Denzin and Y. S. Lincoln, eds. 1998. Strategies of qualitative enquiry. Londen: Sage, pp.56-85.

Nardi, B. A., Whittaker, S. and Bradner, E., 2000. Interaction and outeraction: Instant messaging in action, [online] Available at: $<$ http://dl.acm.org/citation.cfm?id=358975\&bnc=1 $>$ [Accessed 20 July 2012].

Newhagen, J. E., 2004. Interactivity, dynamic symbol processing, and the emergence of content in human communication. The information society, 20(5), pp.397-402.

Norman, D., 2002. The Design of Everyday Things. New York: Basic Books.

O'Reilly, T., 2003. The Architecture of Participation, O'Reilly Developer Weblogs, [online] Available at:<http://www.oreillynet.com/pub/wlg/3017> [Accessed 20 July 2012].

O'Reilly, T., 2005. What Is Web2.0 - Design Patterns and Business Models for the Next Generation of Software, O'Reilly Radar, [online] Available at:<http://www.oreillynet.com/pub/a/oreilly/tim/news/2005/09/30/what-is-web-20.html> [Accessed 20 July 2012].

Oldenburg, R., 1999. The Great Good Place: Cafes, Coffee Shops, Bookstores, Bars, Hair Salons and Other Hangouts at the Heart of a Community. New York: Marlowe and Company.

Oldenburg, R. and Brissett, D., 1982. The Third Place. Qualitative Sociology, 5(4), pp.265-284.

Papacharissi, Z., 2008. The virtual sphere 2.0. In: A. Chadwick and P. N. Howard, eds. 2008. Routledge Handbook of Internet Politics. Abingdon: Routledge, pp.230-245. 
Patmore, C., Qureshi, H. and Nicholas, E., 2001. Consulting older community care clients about their services: some lessons for researchers and service managers. Research Policy and Planning, 18(1), pp.4-11.

Patton, M. Q., 2002. Qualitative research and evaluation methods. Thousand Oaks: Sage.

Petersen, S. M., 2008. Loser Generated Content: From Participation to Exploitation, First Monday, [online] Available at:<http://www.uic.edu/htbin/cgiwrap/bin/ojs/index.php/fm/article/viewArticle/2141/1948> [Accessed 20 July 2012].

Pissard, N. and Prieur, C., 2007. Thematic vs. social networks in web 2.0 communities: A case study on Flickr groups, [online] Available at:<http://hal.inria.fr/docs/00/17/69/54/PDF/42-algotelflickr.pdf > [Accessed 20 July 2012].

Prieur, C., Cardon, D., Beuscart, J.-S., Pissard, N. and Pons, P., 2008. The Strength of Weak cooperation, [online] Available at:<http://arxiv.org/ftp/arxiv/papers/0802/0802.2317.pdf > [Accessed 20 July 2012].

Quiring, O., 2009. What do users associate with 'interactivity'? A qualitative study on user schemata. New Media and Society, 11(6), pp.899-920.

Rafaeli, S., 1988. Interactivity: from new media to communication. In: R. P. Hawkins, J. M. Wiemann and S. Pingree, eds. 1988. Advancing communication science: merging mass and interpersonal process. Newbury Park: Sage, pp.110-134.

Reid, F. and Reid, D., 2010. The expressive and conversational affordances of mobile messaging. Behaviour and Information Technology, 29(1), pp.3-22.

Rigby, B., 2008. Mobilizing generation 2.0: a practical guide to using Web 2.0 technologies to recruit, organize, and engage youth. San Fransisco: John Wiley and Sons.

Rosadiuk, A., 2008. About the Design and deviantART, Synoptique, [online] Available at:< http://www.synoptique.ca/core/articles/s11_about_the_design/> [Accessed 20 July 2012].

Scholz, T., 2008. Market Ideology and the Myths of Web 2.0, First Monday, [online] Available at:< http://www.uic.edu/htbin/cgiwrap/bin/ojs/index.php/fm/article/viewArticle/2138/1945> [Accessed 20 July 2012]. 
Sotira, D., 2010. deviantART's tenth birthday, [online] Available at: $\langle$ http://www.youtube.com/watch?v=9O2lRAooUWk> [Accessed 20 July 2012].

Soukup, C., 2006. Computer-mediated communication as a virtual third place: building Oldenburg's great good places on the world wide web. New Media and Society, 8(3), pp.421-440.

Stern, A. and Wakabayashi, C., 2007. Are you ready for web2.0 marketing? J@ pan Inc., 72, pp.6-9

Strauss, A. L. and Corbin, J. M., 1998. Basics of qualtitative research: techniques and procedures for developing grounded theory. Thousand Oaks: Sage.

Szuprowicz, B., 1995. Multimedia networking. New York: McGraw-Hill.

Tremayne, M., 2008. Manipulating interactivity with thematically hyperlinked news texts: a media learning experiment. New Media and Society, 10(5), pp.703-727.

Valafar, M., Rejaie, R. and Willinger, W., 2009. Beyond Friendship Graphs: A Study of User Interactions in Flickr, [online] Available at:<http://dl.acm.org/citation.cfm?id=1592672> [Accessed 20 July 2012].

Zimmer, M., 2008. The Externalities of Search 2.0: The Emerging Privacy Threats when the Drive for the Perfect Search Engine meets Web 2.0, First Monday, [online] Available at:< http://firstmonday.org/htbin/cgiwrap/bin/ojs/index.php/fm/article/view/2136/1944> [Accessed 20 July 2012]. 